\title{
The Digital Twin - Birth of an Integrated System in the Digital Age
}

\author{
Hendrik Wache \\ Chemnitz University of Technology \\ hendrik.wache@wirtschaft.tu-chemnitz.de
}

\author{
Barbara Dinter \\ Chemnitz University of Technology \\ barbara.dinter@wirtschaft.tu-chemnitz.de
}

\begin{abstract}
Today we live in a time where new technologies are developing rapidly. Digitalization and automation are finding their way into various industrial sectors, especially in the area of Industry 4.0. As in previous digitalization efforts in the manufacturing sector, it can be observed that the discourse is strongly concentrated on technological themes, neglecting the overall integration of technologies into the organization. In this paper, we conduct a literature review on the concept of a digital twin, i.e. a simulation-oriented closed loop system consisting of physical and digital components. We map the identified themes to the elements of a socio-technical system to show which issues in the discourse are underrepresented from a managerial point of view in order to provide indications for a more holistic discourse.
\end{abstract}

\section{Introduction}

The megatrend of digitalization covers many areas of today's life such as production, which is of particular economic importance. In this context, the topic of the fourth industrial revolution, known as Industry 4.0 (I4.0) or smart manufacturing, has continued to develop in recent years. The vision of I4.0 is an internet of things and services, where resources, information, objects, and people are linked for value creation [21]. I4.0 is based on so-called cyber-physical systems (CPS), which consist of a physical and a virtual part. The physical systems include actuators and sensors collecting data and transmitting them over a network. The virtual counterparts of the physical systems map the physical parts, monitor them, and use their data to control the actuators of the physical component [3], creating a closed-loop circuit. In this increasingly complex work environment, Digital Twins (DT) are often discussed. They also implement the mentioned closed-loop approach [3], but focus on the simulation of different scenarios.

DT contain various kinds of data, such as product specifications and designs, production process models, operational performance data, and other knowledge representations [46]. Thus, through this consolidation of heterogeneous data, a DT can be considered as a multi-dimensional and multi-layered cognitive artifact. A cognitive artifact is a human-made object, which contains externalized knowledge or memories to help accomplish a task [37]. Thereby, it does not change the human abilities but changes the task of the human from remembering to 'loading' information into the mind instead [37]. Cognitive artifacts can take on different forms such as structural models, flowcharts, work schedules, and also memorized procedures [9]. The DT as a cognitive artifact in the manufacturing field thereby covers multiple dimensions such as product development, production, and maintenance as well as different layers like static models, dynamic processes, and performance measurements [48]. It aids humans with the cognitive processing of huge amounts of information and therefore impacts the routines of the organization it exists within. Cognitive artifacts have a significant influence on organizational work, they have to be placed in the center of organizational routines in order to be able to understand the mutual relationships of routines and artifacts [9].

In organizational research, much work has been contributed about the human agency and its effects on organizational routines in recent years [17]. Human agency, especially at the management level, is important to successfully manage a company in the digital age. However, in the current I4.0 discourse, the exact opposite can be noticed: The focus lies on the artifacts in a merely technical sense. The DT itself is in the center of the discourse, but not its effects on the organization and the human work. Consequently, the impact on organizational routines is neglected. A synthesis of both, artifacts and human agency would be beneficial in order to achieve a balanced conception of new artifacts in organizations [9]. Surveys from practice have shown that a lack of understanding of new technologies results in organizational inertia and that familiar technologies such as simple ERP reports or statistics are preferred to more advanced analytic methods [15]. Therefore, it is very important that digital innovations such as DT are comprehensively examined for organizations. In order to guarantee this, 
the intersection of the cognitive artifact DT with management fields should be discussed. We believe that viewing the DT through a socio-technical lens is a suitable approach. Prior research has indicated that the socio-technical features of I4.0, as well as the sociotechnical impact of I4.0, require further exploration [10]. This also applies to the DT as an approach for realizing the vision of I4.0 [48]. We would like to address this research gap by means of a less technically and more holistically focused DT discussion. As a result, DT can be designed and implemented taking into account relevant factors and stakeholder groups in order to achieve added value in future organizational routines and to better transform existing routines.

Therefore, our research question is: Which managerial fields arise in the context of DT in manufacturing from a socio-technical perspective? The examination of the DT from such a perspective broadens the view on the rarely discussed managerial fields as well as the intensively discussed technical themes. To this end we conducted an inductive literature review on DT. We categorized the themes of the discourse on DT using elements of the work system theory (WST). WST aims at providing a perspective for understanding socio-technical systems in organizations [5]. We then derived complementary management fields to the technical fields, which can be used to show different perspectives on the DT.

The remainder of the paper at hand is structured as follows: First, the foundations of DT are introduced and a short presentation of the WST is given, before the research approach is described. Subsequently, the current research discourse about DT is structured according to the WST and related managerial fields are revealed. Finally, a discussion and conclusions are drawn.

\section{Foundations}

\subsection{Digital Twins}

"A Digital Twin is an integrated multiphysics, multiscale, probabilistic simulation of a [...] system that uses the best available physical models, sensor updates, [...] history, etc., to mirror the life of its corresponding [...] twin." [12:7]. The original purpose of DT was to determine the condition and behavior of an aircraft by mirroring it digitally on the basis of mathematical models, historical, and current data. Since 2012, the concept of a DT has also been discussed in other industries. The application of the concept has been extended from product lifecycle management (PLM) to the manufacturing domain in 2014 [14]. Since then, the number of scientific publications on the topic has increased massively in each successive year [48]. While initially three essential elements (a physical component, a virtual component, and a connection between the two) were identified [14], later five conceptual components were proposed [48]. As such, a DT consists of a physical entity, a virtual entity, a service system, the data, and the connection between them, all parts being equally important. Only a bidirectional data exchange between the virtual and physical objects allows the concept of a DT [27]. Thus, according to this understanding, besides the original three parts, data constitute a central component of a DT, since these are necessary for the creation of new knowledge. Thereby we conclude that on an abstract level, a DT can be seen as a cognitive artifact for the manufacturing context in I4.0. The concept of DT has grown to a virtual-physical concept, which is related to CPS and to the latest definition of a human-enabling interface to the technologies of I4.0. On this basis, we conclude that DT are a comprehensive management vehicle for CPS, which explicitly takes human interaction into account. Thereby the DT can be characterized as a sociotechnical system.

\subsection{Work System Theory}

The WST constitutes a systematic approach to examine the different facets of an information system (IS). It is considered as a theory that focuses on the understanding of IT-reliant systems in organizations, also called work systems. Work systems can be understood as socio-technical systems where humans perform business processes by using resources like information and technology to create products or services [5]. The application of the WST can be achieved with the corresponding method called work system method. This system analysis method aims at understanding and analyzing work systems in business at any level of detail appropriate to its purpose. It contains the work system framework (WSF) that differentiates between the following elements in a work system: Processes and activities, participants, information, technologies, customers, and products/services[5]. Processes and activities in a work system provide products or services to its customers. Persons, who perform the activities in the process are called participants. Information are all informational entities, which are used and created within a work system and are consequently used by processes and activities. Technology includes the hard- and software that is used during the process. The products and services of a work system may be information, physical objects, or actions. The recipient of the products or services is the customer, who can also be 
involved in the value creation process. In addition, there are three elements, which create a context for the work system itself: environment, infrastructure, and strategy. Environment refers to the external factors that can affect a work system and affect its effectiveness and efficiency, like for example stakeholders or policies. Infrastructure is the term for resources that are used by one or more work systems but are managed outside the work system. Strategies refer to different levels of strategy ranging from enterprise over department to work system strategy, which should be supported by the work system. The paper at hand uses the WSF as a lens through which the concept of a DT is examined to gather an understanding of the different aspects of DT that constitute a holistic IS.

\section{Research Approach}

First, a structured inductive literature review [52] of the DT literature was conducted. The terms "Digital Twin" and "Digital Shadow" were searched in the title, abstract, and keywords. No time period was excluded for the review. Since this paper deals with the DT in the IS context, the first database to be searched was AIS eLibrary, which provided only a single (1) paper. This underlines the need to discuss this important concept of I4.0 in the IS domain. Subsequently, the databases ScienceDirect (66), IEEE Xplore (110), and Scopus (132) were searched (retrieval date 19.05.19). After removing duplicates and discarding papers that deal with the topic of DT outside the manufacturing domain, the corpus could be reduced from 309 to 198 papers. A look at the conferences and journals of the papers reveals a thematic focus in the domains of production, manufacturing, and engineering, but also computer and material science, as well as physics, and math.

To portray the current discourse on DT, a toolsupported review procedure was chosen, using Leximancer, a computer-assisted qualitative data analysis tool. It is suitable to provide a broad overview of main themes of the analyzed data [8]. An automatic instead of a manual coding procedure allows for the unbiased inclusion of all parts of the discourse [18] and thus provides a resource-efficient way to capture the current state of the scientific discussion with similar results to time-consuming manual coding [33]. Nevertheless, human sensemaking needs to take place to guarantee robust results. As a second step, the identified themes were deductively mapped to the elements of the WSF. After this mapping, we checked the papers that were assigned to the respective theme by Leximancer (hereinafter referred to as subcorpus) to identify to which extent the aspects of the corresponding WSF element were covered in the subcorpus. Analyzing a socio-technical system like the DT through the WSF as a lens outlines the basic aspects of this work system for a better understanding [6]. Furthermore, the WSF is suitable to depict the operational meaning of new digital technologies like the DT and can help with identifying related challenges [34]. Therefore, we conclude that this kind of mapping allows for the identification of currently scarcely discussed topic fields.

\section{Discussion of the DT as a Work System}

In this section, we present our results of the twostep approach as described above. Table 1 contains WSF Elements and the themes identified by applying Leximancer to the papers of the literature review. This mapping shows which themes contain concepts that correspond to the definition of WSF elements. This procedure yielded managerial fields that appear to only be discussed subliminally or occasionally. As anticipated, the themes identified by Leximancer suggest a rather technical discourse on DT. In the following we discuss the WSF elements and associated themes as well as the emerging managerial fields.

Table 1: DT \& managerial fields

\begin{tabular}{|l|l|l|}
\hline $\begin{array}{l}\text { WSF } \\
\text { Elements }\end{array}$ & $\begin{array}{l}\text { Leximancer } \\
\text { Themes }\end{array}$ & Managerial Fields \\
\hline $\begin{array}{l}\text { Processes \& } \\
\text { Activities }\end{array}$ & Process & $\begin{array}{l}\text { Product Lifecycle } \\
\text { Management }\end{array}$ \\
\hline $\begin{array}{l}\text { Customers \& } \\
\text { Participants }\end{array}$ & Work & $\begin{array}{l}\text { Human Resource } \\
\text { Management, Work } \\
\text { Organization }\end{array}$ \\
\hline Information & Data & $\begin{array}{l}\text { Data Governance; } \\
\text { Knowledge Management }\end{array}$ \\
\hline Technology & $\begin{array}{l}\text { System; } \\
\text { Tobot \& }\end{array}$ & $\begin{array}{l}\text { Enterprise Architecture } \\
\text { Management; Asset \& } \\
\text { Configuration } \\
\text { Management }\end{array}$ \\
\hline $\begin{array}{l}\text { Products \& } \\
\text { Services }\end{array}$ & $\begin{array}{l}\text { Product; } \\
\text { Model }\end{array}$ & $\begin{array}{l}\text { IT Service Management; } \\
\text { Product-Service Systems }\end{array}$ \\
\hline Strategy & - & $\begin{array}{l}\text { Digital Transformation } \\
\text { Management }\end{array}$ \\
\hline Environment & Energy & $\begin{array}{l}\text { Sustainability } \\
\text { Management }\end{array}$ \\
\hline Infrastructure & Network & $\begin{array}{l}\text { Infrastructure } \\
\text { Management }\end{array}$ \\
\hline
\end{tabular}

\subsection{Processes and Activities}

The WSF element "processes and activities" matches most closely with the theme of process. In the corresponding subcorpus, we found multiple papers discussing single aspects along the value creation 
process. Using the WSF as a lens, phases like planning, development, production, and optimization can be seen as connected activities within a process. For example, DT can be regarded as information vehicles along the whole lifecycle of a product [40]. This leads to the related managerial concept of PLM, which manages the products of a company from the idea up until the disposal [44]. Similar to the task of a product data management system, the DT acts as a central data hub for product information [44]. However, the functionality of DT exceeds the functionality of classical PLM systems by providing a bi-directional information flow between physical and virtual components. Hereby not only the observance of a product in the product lifecycle, but also automatic interventions and control mechanisms are enabled [47]. On the other hand, PLM also includes stakeholder perspectives and guarantees access to needed product information in various organizational routines [44], while the human interaction with a DT remains conceptually vague. Big advantages of the DT in the context of PLM are the digital continuity and higherlevel functionalities like product simulations [35]. This leads to the optimization of organizational routines as well as to the removal of product lifecycle phases such as prototyping, which is then performed virtually. DT allow for a broad application range, from design through manufacturing and utilization to the disposal, covering the whole lifecycle [29]. Thus, managers have to consider the lifecycle phases a DT is supposed to support and by whom and how it can be used and interacted with.

\subsection{Customers and Participants}

The WSF elements "customer" and "participant" do not have a clear analog theme in the discussion about DT. Using the WSF element as a lens reveals the neglected aspect of a human actor. Some papers in the discourse consider the role of humans as a mere assistant to a machine in case of set-up or maintenance [13], while other authors controversially see the machine as an assistant to the human operators [26]. Working with DT changes the required skills and capabilities of the workers. Such a change can be addressed by training and education, which falls under the aspect of human resource management.

Good operational performance of a company and the coordination of the selected manufacturing strategy with human resource activities are strongly linked [54]. The introduction of a new technology such as computer integrated manufacturing is accompanied by a change in the skill requirements of employees. For example, deskilling of operators with a simultaneous upskilling of supervisors could be linked with the introduction of computer integrated manufacturing approaches [2]. The same will presumably apply to the introduction of a DT, which will be accompanied by extensive routine changes due to the big functional scope of a DT. For example, the aspect of monitoring operational data by numerous sensors could lead to a shift of the monitoring task from the machine itself to the desk. In addition, automatic data retrieval allows more freedom for decision making processes and faster decision-making. These changes in routines should be considered on the human resource management side.

Furthermore, the general aspect of work organization and working conditions of workers need to be considered. The advancing digitalization impacts the design of factories, since a high degree of autonomy and automation means that previous approaches to workplaces in production have to be revised, e.g. dangerous zones where machines move freely need to be considered [43]. The research on DT is an extension of current research in this area, previously called virtual factory. In addition to the planning/modelling of a factory [19], DT can extend the concept of the virtual factory by simulations and actual control and intervention capabilities through the bidirectional linkage of the actual and virtual factory. In recent years, work organization has been linked, for example, to topics such as lean production, where there a strong emphasis on optimization efforts exists [38]. In addition to traditional topics of work organization such as automation and optimization, risk management at the workplace is becoming relevant again in I4.0 when people work together with moving robotic components in large, complex systems [43].

In this context, it has to be considered that the DT can act autonomously, resulting in a higher risk in the work environment, i.e. artificial intelligence (AI) making decisions instead of a human being. On the other hand, intelligent systems can also use protective mechanisms that function better than human reactions by using simulation scenarios. It must, therefore, be clarified how the work organization deals with DT, e.g. with interventions and decisions of $\mathrm{AI}$ in the workplace of humans, and how the risk can be managed.

\subsection{Information}

The WSF element "information" plays a special role in the context of IS. Information is generated in a work system and is also used to create value. In the theme data, we identified the concepts of sensor data, real-time data, and big data and the related tasks of data acquisition, collection, and analysis [39]. The use of information created by sensors in the context of DT is demonstrated in an application-driven and problemsolving manner, but managerial fields are rarely 
discussed. In the context of IS, it goes without saying, that procedures and methods of data governance need to be applied in order to ensure appropriate data quality. In contrast, the aspect of data governance is discussed in just one single paper of the corpus [42]. We suggest the managerial theme of data governance, to allow a high data quality, availability, and trustworthiness, which is seen as a challenge in the context of DT [42].

Data governance is a rights system at the organizational level that controls the decision-making process for the asset data [23]. It contains five decision domains: Data principles, data quality, metadata, data access, and data lifecycle [23]. A DT in the manufacturing domain can offer various sources of data due to its potentially high number of sensors. The decision domains of metadata and data life cycle are positively impacted by DT because of its integrated and transparent data creation and storage mechanisms as well as the possibility to generate metadata accordingly. However, it poses challenges for the domain of data quality due to the high heterogeneity of data sources like sensors [48]. Since the DT unites data from various sources and business areas, matters such as data ownership, data access management, and rights control can become complicated and might lead to conflicts on an organizational level. From our point of view, it is less a matter of clarifying which new fields are added to data governance but how the existing fields are changed by DT or how to pay attention to them.

Another important aspect in the context of DT is knowledge management. On an organizational level, it deals with the administration of organizational knowledge for the benefit of companies, e.g. to achieve competitive advantages and to increase the ability to innovate [4]. An important function is the reduction of cognitive loads on people when dealing with large amounts of knowledge [4]. IS that promote inter-group knowledge exchange, and provide fast knowledge access as well as just in time learning, have an enabling role in knowledge management [4]. The DT with its central knowledge collection with regard to product, process, and master data [49] in specialized knowledge bases [28] also represents a central IS for knowledge management. This again shows that DT are conceptually close to PLM systems that are used today. In the area of knowledge management, DT could be regarded as a system that has a varying scope of knowledge. Depending on which data sources are used for a DT, the depicted knowledge area can be very extensive (cf. Smart Factories). With smaller DT, e.g. in the area of manufacturing, one would not expect knowledge about classic organizational processes such as human resource management. With wide-ranging
DT solutions, on the other hand, the scope can be substantial, possibly including these processes as well. In general, similar issues as with other knowledgebased systems can be expected with DT. For example, the extraction of domain knowledge from experts is very complex, as is the conversion of domain knowledge into machine-readable information. These issues are already being discussed in various areas, such as mass customization [11].

We conclude that in the context of organizational knowledge management, traditional systems must be distinguished from novel systems such as DT regarding data ownerships and integration options in knowledge management routines. In addition, in I4.0 systems increasingly make decisions autonomously, apply knowledge, and thus change their role from enablers to active participants in value creation [57].

\subsection{Technology}

The WSF element "technology" stands for the hard- and software in a work system and covers numerous themes of the DT discussion. Following this understanding, the themes system, robot, and tool were assigned to the element technology. The systems discussed in DT literature are focused on data and are used in the manufacturing process of products [e.g. 57]. A DT is not independent of other already existing IS of a company. Instead, we found enterprise systems such as enterprise resource planning systems or manufacturing execution systems mentioned as data suppliers for the DT [48]. The design of the cooperation and especially the data flows and integration between the software and hardware systems is therefore of particular importance, making the field of enterprise architecture management a focal topic.

Enterprise architecture incorporates all principles, methods, and models used to design and implement the organizational structure, processes, and information technology (IT) infrastructure [20]. Enterprise architecture management includes, among other things, controlling the introduction and operation of IS [20]. With newly emerging systems like DT in the age of I4.0, care must be taken to use these well-known and established fields such as enterprise architecture management. It has to be examined how the novel systems and the existing ones are to be integrated within the organization, possibly using an agile approach to enterprise architecture management due to the high interconnectedness of the involved components.

As the discourse on DT illustrates, robots and tools are seen as hardware parts that constitute the physical part of the CPS [48]. Monitoring the numerous hardand software assets to get real-time information about 
their position and state becomes increasingly important [31]. Configurable machines should be able to organize themselves and find an ad-hoc solution for an optimal production process. For such an autonomous mode of operation, the modularization of processes and machines is crucial. The basis for this modularization is a fundamental compatibility of the various components. Therefore, we see the area of (IT) asset and configuration management as a fundamental management field for DT. It addresses the administration of large heterogeneous IT infrastructures to observe where assets are located and which status or configuration they are in [25]. Such basic IT infrastructure management tasks must be provided reliably and automatically as the basis for complex manufacturing systems. This also applies to DT, where asset and configuration management now has to deal with extensive CPS. If the underlying IT services fail, e.g. in the network area, companies are at risk of losing the basis for the more sophisticated I4.0 IT services and systems. Organizations must, therefore, ensure that the underlying basic services have a very high level of reliability and availability in order to be able to use systems such as DT productively.

\subsection{Products and Services}

The WSF element "products or services" deals with the actual result of the work system. The absence of a verbalization of the added value that a DT should provide is noticeable. We believe that the themes of product and model most closely match an actual result that represents the added value of the DT. Analytics and simulation appeared to be the most important aspects identified by analyzing the themes product and model (data, knowledge, and simulation models). In respect to services, which a DT performs, the simulation of different scenarios in production is spoken of first and foremost. In this context, simulations based on real process data can be used to optimize a production line [45]. Application cases from product health management, such as the monitoring of current runtime data and parameters, as well as predictive maintenance, are also discussed. Based on our findings we suggest considering the central output of DT as IT services, e.g. an analytics service or a simulation service. For this reason, we consider the area of IT service management as the fundamental management field responsible for the value delivery of a DT covering the 'how' to provide a product or service. IT service management is a key activity to ensure, for example, the services of smart products (based on DT) from planning through operation and phasing out [1], which implies that a DT itself needs PLM for its own services.
For the 'what is provided', it can be seen that DT, with its cyber-physical implementation, are very close to the concept of product-service systems. Product service systems can be regarded as a combination of tangible products and intangible services to satisfy the requirements of a user and are often discussed in the context of reducing environmental impact [7]. This leads us to conclude that DT can support servitization, but it is open whether the physical part of DT remains the property of the producer or passes into the ownership of the consumer. However, it is important that not only the producer or owner manages the physical part as an asset [7], but that the DT can also manage itself independently in the sense of an autonomous system. Supporting [56], we suggest that DT should be regarded as important enablers for the design of new smart product-service systems in organizations.

\subsection{Strategy, Environment, and Infrastructure}

The WSF element "strategy" provides a context to a work system. Even if the strategies of enterprise, department, and work system do not necessarily have to be formalized, they should be aligned [5]. We have been able to find topics related to strategies, such as the changing role of the human factor in the factory as well as the change in current technologies, which leads to the transformation of the business [50]. We identified the aspect of the recurring pattern of transformation in the DT discourse. From this, we conclude that digital transformation management is a strategic management field that is closely linked to the introduction of DT. Digital transformation describes the change process triggered by the use of new technologies in the organization [30]. It needs to be considered that this can entail changes up to the level of the business model when a DT is introduced. Thus, we believe the organizational transformation caused by DT needs to be actively managed.

The WSF element "environment" is concerned with the external factors of a work system, which can influence its efficiency and effectiveness. The theme of energy was found in DT literature in regards to processes, mainly in the form of energy consumption as a type of data to be collected during the production process [55]. Using the WSF element as a lens, we could identify the concept of sustainability, which is described in the context of the positive impacts of DT such as a reduction of time, costs, and resource consumption [53]. The proximity of DT to productservice systems and PLM underlines the link between DT and the topic of organizational sustainability. We conclude that from an environmental perspective sustainability management is an important field to 
consider. In this context, the circular economy is being discussed, a concept that aims to preserve the value of products and resources as long as possible in the economy in order to minimize waste generation [24]. Typical DT services to address this task are, for example, predictive maintenance which can lead to machines remaining usable for longer and continuous monitoring to reduce waste. The DT can support longlasting design and reconfigurability through its simulation capabilities. We believe organizations should consider modern systems such as DT as a means to shrink or close resource loops and thus support the ideas of the circular economy.

The third WSF element outside of a specific work system is "infrastructure". The theme network can be assigned to this element. An important step for the development of DT is securing the communication between the individual system components, which is guaranteed by a network connection. The communication between the individual elements can take place on different levels in increasing context size: on a lower level from machine to machine over communication on factory-level up to cross-factory or even cross-value creation partner-level [48]. By analyzing the subcorpus through the WSF element lens, it became clear, that the managerial field to manage this theme is indeed infrastructure management, as the communication infrastructure is a vital part of the DT [3]. This again supports enterprise architecture management as an important topic as well as IT service management. If one considers the lifecycle approach of DT from design over production to usage, it becomes clear that this infrastructure management spans multiple companies. At the organizational level, this means that mechanisms and agreements must be found in order to operate DT in value creation networks.

\section{Discussion}

In this section, two exemplary themes are used to illustrate how the under-discussed managerial fields in the DT discourse can be elaborated on. It is noticeable that the topic strategy in connection with DT is only scarcely addressed. No paper which argues decisively for a comprehensive strategy for DT was found in the corpus. However, there are already first approaches for maturity models [41], which examine the I4.0 readiness of enterprises and contain a strategy dimension. Yet, it was found that the strategy dimension was the least developed one of an examined company. The authors attribute this to a missing I4.0 roadmap, which indicates the necessity of designing strategies in the DT and I4.0 area. The WST emphasizes the alignment of strategies of a work system with strategies at surrounding hierarchical levels [5] to ensure effectiveness and efficiency. The topic of aligning different strategies, in general, has been addressed [16] and the well-known approach of the strategic alignment model (SAM) has been developed. A dominance on the side of the IT domain can currently be observed in the DT discourse. If one follows the logic of the SAM, it is a possible first step for companies striving for I4.0 to formulate a clear IT strategy, on the basis of which a business strategy can be derived, in order to adapt the business processes accordingly. Thereby the DT can successfully be integrated into the organizational routines. An optimal alignment between the different strategies and a correspondingly high probability of success in the implementation of I4.0 could be achieved through this approach. Another possibility is a hybrid approach called digital business strategy [51], which pursues a balanced fusion of business and IT strategies due to the increasing importance of IT technologies. It might be a promising way to introduce the DT in a way that the triggered transformation even leads to new business models. Therefore, we propose that from the point of view of IS research, a stronger focus should be placed on discussing technical phenomena such as DT in a managerial and strategic context.

Another important concept that was severely underrepresented in the literature review is that of a human actor. It could be verified that the human factor appears only as a minor note in the discourse. The human being is an essential factor in a holistic IS or socio-technical system. Even though in the context of DT and I4.0 there is a huge focus on automation and autonomous acting CPS, a factory still requires humans to work with the machines or at least to maintain them. In this area, there are different approaches regarding the connection between humans and machines. For example a DT framework to model the human-machine collaboration was developed [32]. The DT in the framework includes the human as an integral part of the human-robot hybrid work environment, which needs to ensure, that no harm is caused to the human part in the shared workstation. A different take on human integration in the I4.0 concept is presented by [22]. A so-called social factory connects human workers, machines, and data into a system resembling a social network. In order to enable human workers to engage with the machines using natural language, chatbots are employed to give recommendations or to initiate appropriate actions. As these papers indicate, research regarding the human factor in the context of I4.0 exists, but we argue that the discussion about this important aspect needs to be intensified. 
It should be noted that DT can be seen as a cognitive artifact that can influence organizational routines. In order to design cognitive artifacts in such a way that the human agency is promoted, the design decisions must be at least partially human-centric. Our appeal is, therefore, to open up two lines of research. On the one hand, how DT are to be integrated into the organization and how they change it, and on the other hand, which design principles need to be considered for such systems. One question arises in the context of the DT discourse: Does the human being and the organization have to be adapted in order to be able to use CPS or do the systems have to be designed organization- and human-centric? Arguably one of the reasons that computer-integrated-manufacturing, an early approach to digitalize the production process, failed, is the strong focus on technology and the disregard of implications on organization and human workers [36]. It should be prevented that the upcoming fourth industrial revolution is impeded or even fails because of the same misconception.

\section{Conclusion}

This paper aims to answer the research question which managerial fields might arise in the context of DT as socio-technical systems. For this purpose, a literature review was conducted which examined the DT discourse from the perspective of the WSF in order to derive managerial fields. Based on this, we could show, what the understanding of these managerial fields is. Furthermore, we showed, how DT can be used in these fields and which factors have to be considered. Our work has implications for practice and research. For practice, the paper provides information on which management fields can be affected if a DT is introduced. The paper provides first hints on how a DT can be used in the organization. For research, it could be shown that DT can be classified as cognitive artifacts, which allows the investigation of the effects its introduction has on organizational routines. Nevertheless, the present paper is subject to some limitations. The focus of the literature review was very strict and the managerial fields are still not comprehensive.

Numerous questions arise for future research. We believe that a research agenda can be derived along the WSF, which we would summarize as follows:

- Which changes in PLM result from the use of DT, in particular from the use of simulations?

- Which design paradigm, technology or humancentered, should be followed for the development of DT?
- How autonomous should DT be and how to deal with the risk factor in the context of artificial intelligence in manufacturing?

- Which challenges arise for classical data governance in the age of I4.0?

- What roles do DT play in organizational knowledge management - enabler for humans or active participants?

- How can DT be integrated into existing enterprise architectures and to what extent do they change it?

- How can DT be conceptualized as the basis for product-service systems?

- To what extent do DT change business models and how big is the transformative character in relation to the organizational strategy?

- What effects do DT have on organizational processes, routines, and human work?

- What role do DT play for sustainability management?

- Do company boundaries represent obstacles for DT use, or can a DT be a cross-organizational platform?

We believe that we were able to contribute to practice and research by providing companies with initial managerial fields and by highlighting several research gaps in the DT discourse.

\section{Acknowledgements}

The research in this paper was supported by a grant from the German Ministry for Research and Education (BMBF), project name: Co-TWIN, nr: 02P17D146.

\section{References}

[1] Abramovici, M., J.C. Göbel, and H.B. Dang, "Semantic data management for the development and continuous reconfiguration of smart products and systems", CIRP Annals - Manufacturing Technology 65(1), 2016, pp. 185-188.

[2] Agnew, A., P. Forrester, J. Hassard, and S. Procter, "Deskilling and reskilling within the labour process: The case of computer integrated manufacturing", International Journal of Production Economics 52(3), 1997, pp. 317-324.

[3] Alam, K.M., and A. El Saddik, "C2PS: A digital twin architecture reference model for the cloud-based cyberphysical systems", IEEE Access 5, 2017, pp. 2050-2062.

[4] Alavi, M., and D.E. Leidner, "Review: Knowledge Management and Knowledge Management Systems: Conceptual Foundations and Research Issues", MIS Quarterly 25(1), 2001, pp. 107-136. 
[5] Alter, S., "Work System Theory: Overview of Core Concept, Extensions, and Challenges for the Future", Journal of the Association for Information Systems 14(2), 2013, pp. $72-121$.

[6] Alter, S., "Sociotechnical systems through a work system lens: A possible path for reconciling system conceptualizations, business realities, and humanist values in IS Development", 1st International Workshop on SocioTechnical Perspective in IS Development, (2015).

[7] Baines, T.S., H.W. Lightfoot, S. Evans, et al., "State-ofthe-art in product-service systems", Proceedings of the Institution of Mechanical Engineers, Part B: Journal of Engineering Manufacture 221(10), 2007, pp. 1543-1552.

[8] Crofts, K., and J. Bisman, "Interrogating accountability: An illustration of the use of Leximancer software for qualitative data analysis", Qualitative Research in Accounting \& Management 7(2), 2010, pp. 180-207.

[9] D'Adderio, L., "Artifacts at the centre of routines Performing the material turn in routines theory", Journal of Institutional Economics 7(2), 2011, pp. 197-230.

[10] Davies, R., T. Coole, and A. Smith, "Review of Sociotechnical Considerations to Ensure Successful Implementation of Industry 4.0", Procedia Manufacturing 11(June), 2017, pp. 1288-1295.

[11] Felfernig, A., G. Friedrich, and D. Jannach, "Conceptual modeling for configuration of mass-customizable products", Artificial Intelligence in Engineering 15(2), 2001, pp. 165176.

[12] Glaessgen, E., and D. Stargel, "The Digital Twin Paradigm for Future NASA and U.S. Air Force Vehicles", 53rd Structures, Structural Dynamics and Materials Conference, (2012), 1-14.

[13] Graessler, I., and A. Poehler, "Integration of a digital twin as human representation in a scheduling procedure of a cyber-physical production system", IEEE International Conference on Industrial Engineering and Engineering Management, (2018), 289-293.

[14] Grieves, M., Digital Twin: Manufacturing Excellence through Virtual Factory Replication, 2014.

[15] Hanley, T., A. Daecher, M. Cotteleer, and B. Snidermann, The Industry 4.0 paradox: Overcoming disconnects on the path to digital transformation, 2018.

[16] Henderson, C., and N. Venkatraman, "Strategic Alignment: Leveraging information technology for transforming organizations", Ibm Systems Journal 32(1), 1993, pp. 4-16.

[17] Howard-Grenville, J.A., "The persistence of flexible organizational routines: The role of agency and organizational context", Organization Science 16(6), 2005, pp. 618-636.

[18] Indulska, M., D.S. Hovorka, and J. Recker, "Quantitative approaches to content analysis: Identifying conceptual drift across publication outlets", European Journal of Information Systems 21(1), 2012, pp. 49-69.
[19] Jain, S., N.F. Choong, and K.M. Aye, "Virtual factory: An integrated approach to manufacturing systems modeling", International Journal of Operations and Production Management 21(5-6), 2001, pp. 594-608.

[20] Jonkers, H., M.M. Lankhorst, W.L. Hugo, F. Arbab, H. Bosma, and R.J. Wieringa, "Enterprise architecture: Management tool and blueprint for the organisation", Information Systems Frontiers 8(2), 2006, pp. 63-66.

[21] Kagermann, H., W. Wahlster, and J. Helbig, Recommendations for implementing the strategic initiative INDUSTRIE 4.0: Final report of the Industrie 4.0 Working Group, Frankfurt/Main, 2013.

[22] Kassner, L., P. Hirmer, M. Wieland, F. Steimle, J. Königsberger, and B. Mitschang, "The Social Factory: Connecting People, Machines and Data in Manufacturing for Context-Aware Exception Escalation", 50th Hawaii International Conference on System Sciences, (2017), 1673 1682 .

[23] Khatri, V., and C. V. Brown, "Designing data governance", Communications of the ACM 53(1), 2010, pp. $148-152$.

[24] Kjaer, L.L., D.C.A. Pigosso, M. Niero, N.M. Bech, and T.C. McAloone, "Product/Service-Systems for a Circular Economy: The Route to Decoupling Economic Growth from Resource Consumption?", Journal of Industrial Ecology 23(1), 2019, pp. 22-35.

[25] Koch, T.E., E. Gelle, and P. Sager, “Automating the configuration of IT asset management in industrial automation systems", 12th IEEE International Conference and Workshops on the Engineering of Computer-Based Systems, (2005), 306-311.

[26] Kousi, N., C. Gkournelos, S. Aivaliotis, C. Giannoulis, G. Michalos, and S. Makris, "Digital twin for adaptation of robots' behavior in flexible robotic assembly lines", Procedia Manufacturing 28, 2019, pp. 121-126.

[27] Kritzinger, W., M. Karner, G. Traar, J. Henjes, and W. Sihn, "Digital Twin in manufacturing: A categorical literature review and classification", IFAC-PapersOnLine 5l(11), 2018, pp. 1016-1022.

[28] Landolfi, G., S. Menato, M. Sorlini, et al., "Intelligent value chain management framework for customized assistive healthcare devices", Procedia CIRP 67, 2018, pp. 583-588.

[29] Lee, S.G., Y.S. Ma, G.L. Thimm, and J. Verstraeten, "Product lifecycle management in aviation maintenance, repair and overhaul", Computers in Industry 59(2-3), 2008, pp. 296-303.

[30] Legner, C., T. Eymann, T. Hess, et al., "Digitalization: Opportunity and Challenge for the Business and Information Systems Engineering Community", Business and Information Systems Engineering 59(4), 2017, pp. 301-308.

[31] Lutters, E., "Pilot Production Environments Driven By Digital Twins", South African Journal of Industrial Engineering 29(3), 2018, pp. 40-53. 
[32] Malik, A.A., and A. Bilberg, "Digital twins of human robot collaboration in a production setting", Procedia Manufacturing 17, 2018, pp. 278-285.

[33] Martin, N.J., and J.L. Rice, "Profiling Enterprise Risks in Large Computer Companies Using the Leximancer Software Tool", Risk Management 9(3), 2007, pp. 188-206.

[34] Matzner, M., M. Büttgen, H. Demirkan, et al., "Digital Transformation in Service Management", Journal of Service Management Research 2(2), 2018, pp. 3-21.

[35] Modoni, G.E., E.G. Caldarola, M. Sacco, and W. Terkaj, "Synchronizing physical and digital factory: Benefits and technical challenges", Procedia CIRP 79, 2019, pp. 472-477.

[36] Noehring, F., R. Woestmann, T. Wienzek, and J. Deuse, "Socio-Technical Capability Assessment to Support Implementation of Cyber-Physical Production Systems in Line with People and Organization", International Conference on Human Factors and Systems Interaction, (2019), 299-311.

[37] Norman, D.A., Things That Make Us Smart: Defending Human Attributes in the Age of the Machine, AddisonWesley Longman Publishing Co., Inc., Boston, MA, USA, 1993.

[38] Olivella, J., L. Cuatrecasas, and N. Gavilan, "Work organisation practices for lean production", Journal of Manufacturing Technology Management 19(7), 2008, pp. 798-811.

[39] Qi, Q., and F. Tao, "Digital Twin and Big Data Towards Smart Manufacturing and Industry 4.0: 360 Degree Comparison", IEEE Access 6, 2018, pp. 3585-3593.

[40] Schleich, B., K. Wärmefjord, R. Söderberg, and S. Wartzack, "Geometrical Variations Management 4.0: towards next Generation Geometry Assurance", Procedia CIRP 75, 2018, pp. 3-10.

[41] Schumacher, A., S. Erol, and W. Sihn, "A Maturity Model for Assessing Industry 4.0 Readiness and Maturity of Manufacturing Enterprises", Procedia CIRP 52, 2016, pp. 161-166.

[42] Shao, G., and D. Kibira, "Digital manufacturing: Requirements and challenges for implementing digital surrogates", Proceedings of the 2018 Winter Simulation Conference, IEEE (2019), 1226-1237.

[43] Smith, M.J., and P. Carayon, "New technology, automation, and work organization: stress problems and improved technology implementation strategies", The International journal of human factors in manufacturing 5(1), 1995, pp. 99-116.

[44] Stark, J., Product Lifecycle Management (Volume 1) 21 st Century Paradigm for Product Realisation, Springer, Heidelberg, 2009.
[45] Sujová, E., H. Čierna, and I. Zabińska, “Application of digitization procedures of production in practice",

Management Systems in Production Engineering 27(1), 2019, pp. 23-28.

[46] Tao, F., J. Cheng, Q. Qi, M. Zhang, H. Zhang, and F. Sui, "Digital twin-driven product design, manufacturing and service with big data", International Journal of Advanced Manufacturing Technology 94(9-12), 2018, pp. 3563-3576.

[47] Tao, F., Y. Wang, Y. Zuo, H. Yang, and M. Zhang, "Internet of Things in product life-cycle energy management", Journal of Industrial Information Integration 1, 2016, pp. 26-39.

[48] Tao, F., M. Zhang, and A.Y.C. Nee, Digital Twin Driven Smart Manufacturing, Academic Press, London, 2019.

[49] Umeda, Y., J. Ota, F. Kojima, et al., "Development of an education program for digital manufacturing system engineers based on 'Digital Triplet' concept", Procedia Manufacturing 31, 2019, pp. 363-369.

[50] Vachalek, J., L. Bartalsky, O. Rovny, D. Sismisova, M. Morhac, and M. Loksik, "The digital twin of an industrial production line within the industry 4.0 concept", 21st International Conference on Process Control, (2017), 258262.

[51] Venkatesh, V., M.G. Morris, G.B. Davis, and F.D. Davis, "Digital Business Strategy: Toward a Next Generation of Insights", MIS Quarterly 27(3), 2014, pp. 425-478.

[52] Webster, J., and R.T. Watson, "Analyzing the Past to Prepare for the Future: Writing a Literature Review.", MIS Quarterly 26(2), 2002, pp. xiii-xxiii.

[53] Xiang, F., Z. Zhi, and G. Jiang, "Digital twins technolgy and its data fusion in iron and steel product life cycle", 15th IEEE International Conference on Networking, Sensing and Control, (2018), 1-5.

[54] Youndt, M.A., S.A. Snell, J.W.J. Dean, and D.P. Lepak, "Human Resource Management, Manufacturing Strategy, and Firm Performance", The Academy of Management Journal 39(4), 1996, pp. 836-866.

[55] Zhang, M., Y. Zuo, and F. Tao, "Equipment Energy Consumption Management in Digital Twin Shopfloor: A Framework and Potential Applications", 15th IEEE International Conference on Networking, Sensing and Control, (2018), 1-5.

[56] Zheng, P., T.J. Lin, C.H. Chen, and X. Xu, "A systematic design approach for service innovation of smart product-service systems", Journal of Cleaner Production 201(August), 2018, pp. 657-667.

[57] Zhong, R.Y., X. Xu, E. Klotz, and S.T. Newman, "Intelligent Manufacturing in the Context of Industry 4.0: A Review”, Engineering 3(5), 2017, pp. 616-630. 